\title{
A digital servitization framework for viable manufacturing companies
}

\author{
Maria Vincenza Ciasullo \\ Department of Management and Innovation Systems, University of Salerno, Fisciano, Italy; \\ Department of Management, University of Isfahan, Iran and Swinburne University of Technology, Sarawak, Malaysia, and \\ Francesco Polese, Raffaella Montera and Luca Carrubbo \\ Department of Management and Innovation Systems, University of Salerno, Fisciano, Italy
}

\begin{abstract}
Purpose - The purpose of this paper is to understand the strategic management of a technology-enabled shift from a product-centric to a servicecentric logic and to identify the sociotechnical dynamics underlying this transition. The study focuses on how manufacturers manage to create value in industrial markets through digital servitization.

Design/methodology/approach - An abductive research approach is used to investigate two manufacturing firms, and an interpretive framework is used as an analytical template. A cross-case analysis is conducted.

Findings - The case companies strategically managed sociotechnical processes of digitization to co-create value. Their service orientation delineates dissimilarity in terms of digital servitization. It reflects a viable ecosystem that moves toward datatization through adaptation in one case and a viable ecosystem that moves toward digitization through reconfiguration in the other case.

Practical implications - A theoretically grounded, empirically informed framework is proposed to detect transformational mechanisms to manage value co-creation in digitally servitized contexts, thus contributing to ecosystem viability.

Originality/value - This is the first study to adopt a system perspective such as the viable system approach combined with service-dominant logic to reconceptualize the overall sociotechnical processes and the underlying mechanisms leading to digitized value creation. In line with a systems view and a systematic process based on a transformative attitude toward digital servitization, the empirically informed framework identifies specific co-creation activities and recursive feedback loops.
\end{abstract}

Keywords Value co-creation, Manufacturing firms, B2B markets, Digital servitization, Viable system approach

Paper type Research paper

\section{Introduction}

The current era is marked by perpetual change, high uncertainty and growing complexity fueled by the digital revolution (Savić, 2019). Emerging technologies (i.e. internet of things [IoT], blockchain, big data, cloud computing platforms and robotics) have made possible strong connectivity among people and organizations in interactive ecosystems where unprecedented value can be created and exchanged (Ramaswamy, 2020). The transition toward digitization has generated profound changes in the managerial mindset, organizational layouts, relationship management and decision-making processes (Kowalkowski et al., 2013; Breidbach and Maglio, 2016). Organizations competing in business-to-business (B2B) markets are not immune to these transformations because digitization alters value communication, appropriation, measurement and representation. Technology breakthroughs, triggering a new mindset, push digital servitization, i.e. the use of digital

The current issue and full text archive of this journal is available on Emerald Insight at: https://www.emerald.com/insight/0885-8624.htm

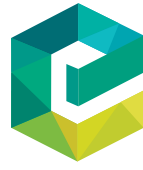

Journal of Business \& Industrial Marketing 36/13 (2021) 142-160

Emerald Publishing Limited [ISSN 0885-8624] [DOI 10.1108/JBIM-07-2020-0349] technology to sustain the shift from a product-centric to a service-centric logic (Coreynen et al., 2017). The transition to service seems far from easy because it adds complexity that entails changes in business orientation (Sklyar et al., 2019), as well as a reconfiguration of value creation processes (Hakanen et al., 2017).

The literature has identified three research gaps in this research stream. First, the digital servitization of industrial companies, especially in manufacturing settings, remains under-investigated (Paschou et al., 2018; Kohtamäki et al., 2020). In this field, B2B is studied less than business-toconsumer (B2C) given the greater complexity of industrial markets in terms of resource heterogeneity, changes in contextual conditions, mistakes, conflicts and misalignments

\footnotetext{
(C) Maria Vincenza Ciasullo, Francesco Polese, Raffaella Montera and Luca Carrubbo. Published by Emerald Publishing Limited. This article is published under the Creative Commons Attribution (CC BY 4.0) licence. Anyone may reproduce, distribute, translate and create derivative works of this article (for both commercial \& non-commercial purposes), subject to full attribution to the original publication and authors. The full terms of this licence may be seen at http://creativecommons.org/licences/by/4.0/ legalcode
}

Received 22 July 2020

Revised 24 December 2020

16 February 2021

14 April 2021

Accepted 15 April 2021 
among actors (Gebauer et al., 2020). Second, scholars have called for theoretical development based on conceptual pluralism and the use of well-established theories from adjacent mature fields to endow servitization-related research with higher-order components (Kowalkowski et al., 2017; Luoto et al., 2017; Kohtamäki et al., 2019). Third, several studies have investigated dyads, neglecting the higher levels of analysis required to further develop servitization theory, as a digital transition to service not only occurs within a manufacturer and its customers but also requires involving suppliers, partners and even competitors, thus calling for multiple and interacting cocreation links (Martin et al., 2019).

Such gaps inevitably increase the complexity faced by scholars and B2B organizations in identifying which theoretical approaches and practices are effective in harnessing the potential of digitization in servitization research.

Against this backdrop, the present paper aims to understand the strategic management of the technology-enabled shift from a product-centric to a service-centric logic and to identify the sociotechnical dynamics underlying this transition. Accordingly, the leading research question is how do manufacturers manage digital servitization to create value in industrial markets?

Theoretically, to accomplish the complexity in which digital servitization is rooted, a systems approach is adopted (Barile et al., 2012a; Barile et al., 2016). Accordingly, B2B is considered a system because actions depend on and influence other actors' actions, entailing mutual dependence among inter- and intra-systemic actors' interactions (Gummesson and Polese, 2009; Polese et al., 2017a). This perspective is extended to the marketing literature by the viable systems approach (VSA) (Golinelli, 2010; Barile and Polese, 2010). These themes are echoed by service-dominant (S-D) logic, where value co-created by actors influences ecosystem viability (Vargo and Lusch, 2011; Polese et al., 2017b). Thus, an interpretive framework of digital servitization is defined that combines VSA and S-D logic to reconceptualize the overall sociotechnical processes and the underlying mechanisms leading to digitized value creation. Empirically, we designed a qualitative study involving two B2B manufacturing systems to explore how key drivers can lead to the emergence of different digitized outcomes.

The paper contributes to the body of knowledge on both servitization and digitalization in three ways. First, this research field is endowed with a greater conceptual component, as the findings reveal the contribution of service orientation to digitization in manufacturing. Thus, we suggest that digital servitization implies changes occurring in focal firms and other actors, engaging the whole service ecosystem in transformations to achieve viability. Second, we provide a theoretically grounded, empirically informed framework to detect the transformational mechanisms needed to achieve and manage value co-creation in digitally servitized contexts. Third, we provide additional research on the micro-foundations of value co-creation, analyzing the activities co-created between interacting actors and identifying specific digital servitized pathways that revisit service exchange through new valuecreating opportunities enabled by digital technology (Paschou et al, 2020).
The article proceeds as follows. Section 2 contains a literature review on digital servitization and describes the interpretive framework proposed to reread the phenomenon. Section 3 explains the research methodology. Sections 4 and 5 outline and discuss the research findings. Finally, Section 6 proposes the main study implications.

\section{Theoretical background}

\subsection{Digital servitization}

The interplay between digitization and servitization falls under the umbrella of digital servitization (Kohtamäki et al., 2020; Paschou et al., 2020). This term refers to how digital technologies enable the delivery of advanced services in innovative ways (Kohtamäki et al., 2019). Digital servitization requires digitization, which means converting analog information into a digital format ( $\mathrm{Ng}$ and Wakenshaw, 2017). Its innovativeness depends on digitalization, which refers to the combination and recombination of digital technologies to create and harvest value in new ways (Svahn et al., 2017). A wide range of digital systems and interfaces (i.e. IoT, big data, artificial intelligence, cloud computing, etc.) (Rymaszewska et al., 2017) need to be managed to shift from a product-centric to a service-centric logic (Sklyar et al., 2019).

Previous research has highlighted both opportunities and challenges for industrial organizations in undertaking digital servitization, although this research stream is in its infancy (Kohtamäki et al., 2020). Focusing on opportunities, manufacturers can exploit digital servitization to enhance both internal and external processes. Internally, manufacturers can improve operational efficiency through automation (Coreynen et al., 2017). Externally, digitization enables companies to integrate their processes with customers' value processes, generating innovative solutions for competing in complex markets (Ulaga and Reinartz, 2011; Grandinetti et al., 2020). To respond to challenges, companies need to reconfigure their organizational behaviors. In the cases of separate service/ product units, it is a challenge to balance the interests of such units to achieve a consistent decision-making process (Vendrell-Herrero et al., 2018). Another challenge concern unlearning an obsolete product-related mindset and routines in favor of service orientation and behaviors to increase customer value (Storbacka and Nenonen, 2015). This requires significant investment in Industry 4.0, coupled with the recruitment of people with the capability to harness digitalization (Kohtamäki et al., 2019). Moreover, there is a need for investment in relationships because transactional product-centric relationships must be revised and adapted to interactions (Reim et al., 2018). Hence, digital transformation implies boundary-spanning activities that lead to the establishment of new partnerships (Tronvoll et al., 2020). Nevertheless, manufacturers seem to struggle with the deployment of digitization. Industrial marketing scholars have highlighted the need to understand the strategic configurations that industrial companies must orchestrate to achieve digital servitization (Kohtamäki et al., 2019). Moreover, the literature contends that digital servitization can emerge from tightly coupled interactions among technological innovations and collaborative innovations. 
On this basis, we argue that industrial organizations need to innovate both their market offerings and business processes by embracing an all-encompassing service mindset grounded on open organizational models and co-developing digital capabilities through complex patterns of coordination, cooperation and integration.

\subsection{Theoretical roots of digital servitization framework}

To interpret digital servitization, S-D logic and VSA are combined as the theoretical foundations.

S-D logic (Vargo and Lusch, 2008, 2016, 2017) is a scientific-cultural approach that aims for value co-creation in systems of service-for-service exchange based on the premise that service - the application of one actor's resources for the benefit of another - is the foundation of social and economic exchanges. S-D logic portrays markets as dynamic and socially constructed systems that are driven by resource integration (Akaka et al., 2012). VSA embraces a holistic view halfway between viewing organizations as a set of interacting components and the willingness to explore ways to survive in evolving environments (Barile and Polese, 2010). It is based upon viable systems, as interacting service systems are dynamic configurations of resources connected internally and externally through value propositions (Maglio et al., 2006; Barile et al., 2012a).

On the one hand, S-D logic is used to understand manufacturers' shift from a traditional value-in-exchange product orientation to a servitized value-in-use interactional orientation. More specifically, S-D logic constitutes a revealing lens to understand value as co-created within the digital servitization context. Co-creation of value is intended as a complex, "joint, collaborative, concurrent, peer-like process of producing new value, both materially and symbolically" (Galvagno and Dalli, 2014, p. 644). On the other hand, the key theoretical insights of VSA are considered.

First, VSA embraces a constructivist view according to which each entity builds the observed reality according to its own information variety (Barile, 2009). In fact, any observed phenomenon can be investigated by analyzing the parts of a system and the whole system (how it is made) and by interpreting its dynamics as an open system (how it behaves) (Barile et al., 2016). System behavior can be understood by identifying other relevant systems and the multiple influences that they exert on the focal system. Such systems shape interconnected networks that can create new entities and innovative episodes of mutual value creation.

Second, VSA refers to the conditions for viability, defined as the ability of a system to restore its point of equilibrium within a specific relational context, in which sub-systems and suprasystems are harmonically integrated, survive and co-evolve (Barile et al., 2013). This implies that their expectations and goals need to be harmonized to enable effective service-forservice interactions. This aspect allows us to recall the notions of consonance and resonance that foster the viability of the system as a whole (Barile and Polese, 2010).

Third, VSA addresses the role of decision-making for system viability, which is particularly relevant in value co-creation contexts under uncertain conditions. Based on the ability of management to decide and creatively resolve intricate problems, a system can react and adapt to changes (Polese et al., 2017b).

\subsection{Digital servitization framework design}

By integrating S-D logic and VSA in the digital servitization domain, specific dynamics are contemplated. The focus is broadening the strategic role of the value creation process in ensuring ecosystem viability (Polese et al., 2018a). Thus, a holistic understanding of digital servitization is proposed to break the complexity of the phenomenon into smaller and more manageable building blocks named antecedents, viability mechanisms and outcomes (Figure 1).

The framework represents an iterative and nonlinear process that dynamically evolves through the interplay of the building blocks. Additionally, the framework has a multidirectional nature because the building blocks exist in a state of dynamic interdependency. The conceptual foundations of the framework support this multi-directionality: S-D logic considers value co-creation a cyclical interactive process (Powers et al., 2016), while VSA suggests viability mechanisms that can shape the self-adjustments of systems. Therefore, changes to any building block can ripple through the framework in a variety of directions.

\subsubsection{Antecedents}

Stakeholder selection consists of selecting the various suprasystems according to the critical resources they own and their influence on the system's viability (Barile and Polese, 2010). The relevant resources for viable systems are operant resources consisting of a knowledge endowment that expresses value, not in itself (objectively) but through its use (as the value in use) (Vargo and Lusch, 2011). This implies interactions with other viable systems that possess those resources to gain access to them (Barile and Saviano, 2013). Moreover, stakeholders' selection is oriented toward supra-systems that comply structurally with the organization and have a set of values that are widely shareable, fostering stable inter- and intra-systemic relationships. Once such relationships are established, the supra-systems become actors embedded in the emergent relational context as a limbo that contains potential partners such as suppliers, customers, investors and other co-makers. Sub-systems refer to the physical organizational structure, including operand and operant resources (i.e. equipment, facilities and people).

Actors are service-providing and value-creating entities that engage in value propositions with other entities leveraging digital platforms. The system embraces a diversity of actors as viable systems (Barile and Saviano, 2013) with different goals but the same need to survive in a specific context (Polese et al., 2017b). These entities accommodate both human (people) and non-human (machines and technologies) actors rooted in systemic value co-creation (Breidbach and Maglio, 2016). Thus, the role of non-human actors challenges the conventional view of technology, emphasizing that digital is more than a mere mediator of $\mathrm{B} 2 \mathrm{~B}$ transactions because it gives rise to new value-creating opportunities (Kaartemo et al., 2019). This mixture of humans and smart solutions open business relationships to complex and rich interaction patterns ranging from dyads to triads and ecosystems (Storbacka, 2018). 
Figure 1 Digital servitization framework

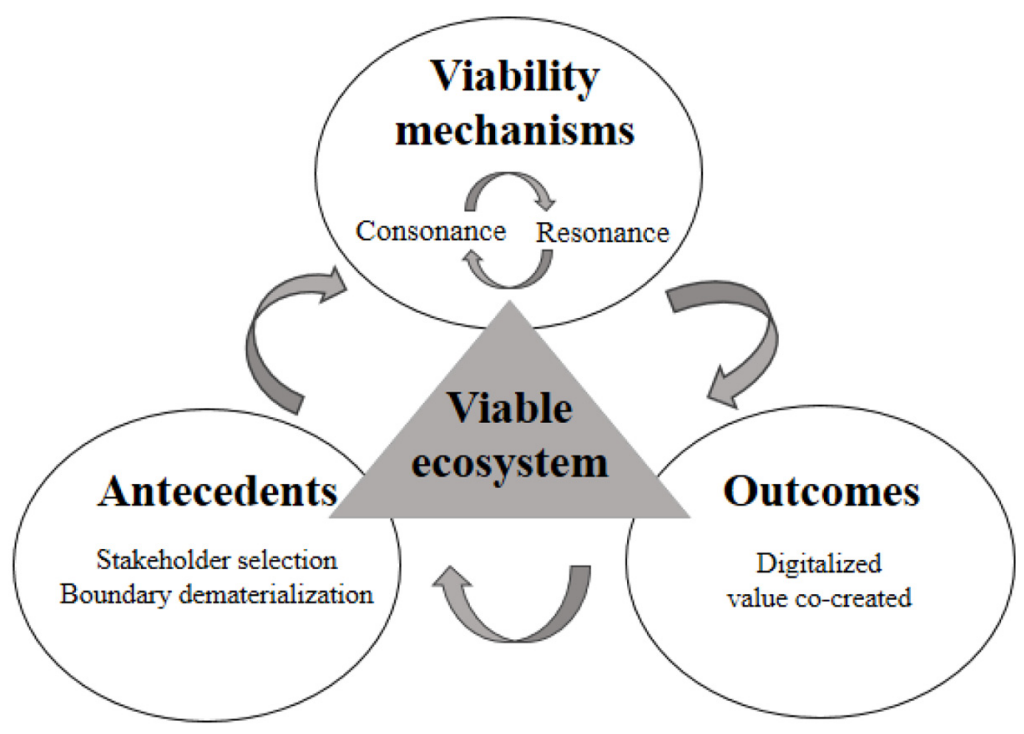

Source: Authors' elaboration

When resources from multiple sources are integrated into a specific context, actors become agents of value co-creation (Vargo and Lusch, 2016). Rather than being manufactured and delivered, value is co-created by involved actors willing to collaborate to improve this integration process. Thus, value cocreation broadens two-way supplier-firm or firm-customer interactions to various relations of artifacts, processes, interfaces and persons (Ramaswamy and Ozcan, 2018). Actors provide benefits to other parties involved in the exchanges and contextually generate positive effects for the whole system to which they belong, looking ahead to results in the medium and long term (Polese et al., 2017b). Service interactions foster the emergence of a viable ecosystem in which the value of the whole system is greater than the sum of the value of its parts. An actor represents the "foundation resource," the "key determinator" (Tronvoll, 2017, p. 8) in-service ecosystems because he/she/it performs roles not performed by other resources or processes. Finally, actors can be present in other actors' processes; this enables new types of organizational structures, institutions and practices that become more malleable, paving the way for ongoing innovations.

The gradual fulfillment of common value creation involving different actors blurs distinctions between focal enterprises, other enterprises and the environment (Barile et al., 2016). According to VSA, boundaries can be identified only at a structural level, as they vanish at a systemic level (Barile et al., $2012 b$ ). System organizations should open their boundaries to collaborate and co-evolve along with their relevant stakeholders (Polese et al., 2018b). Hence, a digital transition to service requires the capacity to co-create across firm boundaries, as smart solutions must be designed to interact with the solutions of other firms used by customers, delivered by distributors, maintained by partners and operated by third parties (Sklyar et al., 2019).

This leads to boundary dematerialization, referred to as open connections within and among sociotechnical systems for the exchange of resources. In addition, dematerialization is strengthened by resource density in terms of the degree to which the technology-enabled mobilization of resources takes place (Normann, 2001). The huge availability of data and advanced analytics allows new systemic collaborative structures that blur traditional actors' roles, making access to both physical and sociocultural resources relatively easier and cheaper (Storbacka et al., 2012). Moreover, digitization provides endless opportunities for the liquefaction of resources, which means decoupling from their physical form, allowing them to be easily moved and accessed in any time and space (Storbacka, 2018).

\subsubsection{Viability mechanisms}

Consonance and resonance act as crucial mechanisms among system elements and the relational context to achieve viability (Barile and Polese, 2010). While consonance reflects the interacting actors' abilities to optimize available resources in their interaction episodes, resonance represents the virtuous orientation toward increasing returns over time (Barile et al., 2012a). Consonance defines the condition for effective interaction, making entities aware of belonging to the same context with mutual goals. Moreover, it refers to the compatibility or configurational fit between systemic actors in terms of shared value categories providing resource compatibility. When different actors harmonically collaborate to achieve a common purpose, consonance emerges from the relation by ensuring stability and growth for the parties involved (Gummesson et al., 2010).

Resonance is a behavioral mechanism describing interaction success that increases system viability (Polese et al., 2018a, $2018 b, 2018 c$ ). In the digital servitization context, actors should play an active role in jointly creating value (Sjödin et al., 2020). Value is co-created when actors' interactions are based on a structural consonance that leads to value alignment for achieving shared purposes (Barile et al., 2016). Key aspects are the mutual exchange and integration of resources - such as capabilities, skills, information and experience - in the actors' 
reality (Vargo and Lusch, 2008). In sum, a system is viable if it is able to create and sustain inter- and intra-systemic relationships through synergic resource integration and to seek cooperation by adhering to a win-win logic, thereby facilitating a range of co-creative activities (Polese et al., 2018b). Moreover, to achieve viability, the system has to preserve its stability through complementary feedback mechanisms (Batista et al., 2017).

This set of viability mechanisms allows a system facing variety to preserve its stability through a range of activities related to adaptation, transformation and reconfiguration at the organizational, business and identity levels (Barile, 2009). These activities depend on actors' ability to subjectively analyze the environment and to proactively influence it. This proactive condition supports viable value co-creation because it stimulates consonance, improves co-creative activities and allows cognitive and profitable alignment (Pels et al., 2014). In other words, this capability refers to decision-making under complexity (Barile, 2009). It should improve dynamic and continuous learning, in which knowledge is continually reorganized and adapted, into a higher-level learning process. Therefore, the learning process should involve other actors because the aim is not only learning within the system but also as a system (Storbacka and Nenonen, 2015). Decision-making needs to ensure a real-time and circular exchange of knowledge among all actors (Ciasullo, 2018; Polese et al., 2018c) with the aim of fostering informative and cognitive alignment. Each actor should be guided by a collaborative spirit and feel that he/ she is an integral part of a net of relationships oriented toward value co-creation. Harmonic and more diffuse decision-making takes place within the co-creation process because the strategic direction involves all actors in the co-development of innovations and generation of ideas for product-service integration and provision (Lusch and Vargo, 2014).

\subsubsection{Outcomes}

Outcomes of the co-creation process are related to the value whose systemic nature makes it subjective (the process cannot be measured as embedded in objects and is evaluated by adopting a specific perspective) and emergent (it cannot be evaluated with a static and structural perspective but needs a dynamic and systems view). In addition, the value is contextual (the process through which it is created dynamically depends on the conditions of the relational context) and interactional (implying a multi-actor process).

Outcomes for manufacturers overcome the economic value of the financial benefits due to digital servitization (Martin et al., 2019). As the servitization literature states, digitization is intended to enable more effective and efficient value creation and capture through a variety of software components, thereby implementing smart platforms (Kohtamäki et al., 2020). This implies that outcomes derive from multiple interactions in terms of value that are obtained from investments in digitization and captured by interacting actors according to their real expectations of growing mutual satisfaction (Polese et al., 2017a). Both strategic and relational value emerge. Strategic value reinforces higher competitiveness (i.e. access to new markets) because it is based on knowledge comprising the innovation opportunities deriving from digital servitization (i.e. customer knowledge, user knowledge, and external market knowledge). As the knowledge endowment of interacting viable systems influences the outcomes of the co-creation process, such outcomes can be read as cognitive processes that characterize the functioning of viable systems (Barile and Saviano, 2013). Relational value refers to the legitimacy of the manufacturer to manage relationships with several actors, aligning their positions and activities around common value creation in a process of resource sharing aimed at developing synergies in the creation of a new value proposition at the core of the system (Barile et al., 2013). On this basis, there is a need to consider value multidimensional, requiring its analysis in light of the viability mechanisms among interacting actors.

\section{Methodology}

\subsection{Research strategy}

Given the limited research on digital servitization in manufacturing companies (Paschou et al., 2018; Kohtamäki et al., 2020), we adopted an abductive research strategy based on an integrated approach to the theory, literature, and emerging data (Dubois and Gadde, 2002, 2014), constantly moving "back and forth between a set of observations and theoretical generalizations" (Tavory and Timmermans, 2014, p. 4). More in-depth, we used S-D logic and VSA approach as sensitizing concepts to help us set the direction of our study. These theoretical lenses enabled us to propose an interpretative framework as a general sense of reference and guidance in which the main dimensions (i.e. building blocks) are proposed. By switching from theory and empirical observations several times, we applied the framework proposed, and then enriched it through an in-depth case analysis (Gummesson, 2017). We then returned to the theory to apply our new findings to the existing literature, highlighting our contribution. This implied matching of different research activities to expand the understanding of the theory and empirical context since empirical findings and theoretical considerations are alternated and combined, providing a holistic and rich description of digital servitization in industrial settings.

\subsection{Research setting and data collection}

An exploratory case study research design included two B2B companies and a cross-case analysis (Eisenhardt and Graebner, 2007). Adopting the viewpoint of the focal actor, an in-depth investigation was performed to analyze how manufacturers manage digital servitization to create value in industrial markets. We relied on criterion-based theoretical sampling by defining screening parameters to identify suitable cases. The parameters were being $\mathrm{B} 2 \mathrm{~B}$ companies; belonging to the manufacturing industry; being large organizations according to the European Union (i.e. firms with 250 or more employees), with smaller firms excluded based on the assumption that they were not yet ready for a full digital transformation (Ghobakhloo, 2018); having pursued digital servitization over the previous five years; and has received awards in the digital domain. The cases were chosen through an internet search using many keywords (e.g. digital servitization, manufacturing, Industry 4.0 and service 2.0 ) to identify and select informationrich cases (Russo Spena and Mele, 2020). The companies selected under these criteria were identified as "Alpha" and "Beta" to preserve confidentiality. Both are multinational 
manufacturers with headquarters in Europe. Alpha's core offering is based on alcoholic beverages. Beta is an original equipment manufacturer (OEM) that provides industrial and commercial vehicles (Table 1 ).

Data collection lasted 7 months between 2019 and 2020 . Drawing on Yin (2017), multiple data sources were used to ensure construct validity through data triangulation, as recommended for industrial marketing case studies (Goffin et al., 2019). Secondary sources included annual reports and internal documentation, as well as company magazines and business publications and websites. Primary sources consisted of 26 in-depth interviews with key informants across various functions and organizational levels in the two case companies to capture alternative views about the digital servitization transition. To preserve confidentiality, individual informants were anonymized (Table 1 ).

The primary data were collected through exploratory interviews with the help of a semi-structured interview guide aimed at ensuring a comprehensive understanding of the changes - in terms of the antecedents, viability mechanisms, and outcomes - affected by digital servitization (Appendix). The interview design included the introduction and general questions followed by specific ones to contextualize the research aim. They addressed the following insights: challenges and problems experienced by firms; factors that triggered digital servitization and how it has changed the intra- and intersystemic relationships, i.e. within and among internal departments, customers and/or other players (such as suppliers and service providers); main changes in the structure of relational context occurring after digital servitization; practices of value creation occurring with customers and other players, and their impact on other actors' resources and activities; how these practices were managed; finally, effects generated by digital servitization.

The interviews, which lasted approximately $50 \mathrm{~min}$ and were conducted by Skype, were based on open-ended questions, giving to interviewees the freedom to answer, to cover a detailed description of transformations required by digital servitization, and to introduce new elements encouraging the emergence of new issues and questions. The taped interviews were transcribed verbatim and their collection and analysis took place simultaneously. Follow-up discussions by e-mail were used to clarify and validate issues.

\subsection{Data analysis}

We conducted a nonlinear data analysis process, in line with a systematic combining approach, in which "theoretical framework, empirical fieldwork and case analysis evolved simultaneously" (Dubois and Gadde, 2002, p. 554). Following this approach, data analysis was based on thematic analysis that provided ways to identify patterns in a large and complex data set, and effectively and accurately identify links within analytical themes and overarching dimensions (Braun and Clarke, 2006). In so doing, we performed three interrelated phases. The first phase focused on an in-depth analysis of the collected interviews. Each interview was analyzed and coded both deductively, using the sensitizing concepts to "lay the foundation for the data analysis" (Bowen, 2006, p. 14) and inductively to unfold new concepts (Gioia et al., 2013). Then, codes emerged by matching empirical data and the main dimensions of our interpretative framework (i.e. building blocks) to detect the structural and systems dimensions of digital servitization and were repeatedly revised. These codes constituted the foundation for the development of the firstorder categories during the second phase. The latter consisted of comparison, grouping and in-depth examination of the relationships among codes and first-order categories. During the first two phases, the authors first coded individually and then compared the coding results, thereby ensuring a high degree of inter-coder reliability. Data analysis and coding process were compared, and if disagreements occurred, discussions followed to improve coherence.

In the third phase, the first-order categories were examined and used to discover links and patterns within them. Such iterative process generated second-order themes that

Table 1 Case companies' profile and data collection

\begin{tabular}{lll}
\hline & Alpha & Beta \\
\hline Main offering & Beer, wine and cider & Trucks and light commercial vehicles \\
Size & Employees: 266 & Employees: 302 \\
& Revenue: $€ 26.8 \mathrm{~m}$ & Revenue: $€ 110.4 \mathrm{bn}$ \\
Main industrial markets & Europe, Americas & Europe, Americas, Asia Pacific \\
Location of the unit interviewed & Spain & Italy \\
Number of interviews & 12 & 14 \\
Informant position & General manager: 1 & General manager: 1 \\
& Software specialists: 2 & Digital services manager: 1 \\
& Tool managers: 4 & Service engineers: 2 \\
& Customer solution manager: 1 & Platform development managers: 3 \\
& Regional manager: 1 & Vice president of customer segment: 1 \\
Interview length & Sales director: 1 & Integrated operations manager: 2 \\
Interview type & Marketing manager: 1 & Global technical support manager: 1 \\
Source: Authors' elaboration & Technology manager: 1 & Embedded systems coordinators: 2 \\
\hline
\end{tabular}


adequately captured the phenomena observed in the first-order categories. In this phase, the goal was to identify the enabling mechanisms and their dynamic interplay involved in digital servitization patterns. To meet theoretical aims, in the description of the findings the main mechanisms are grouped into the key dimensions, which then provided the structure for how the themes converged into dimensions of our interpretative framework. They captured the structural and systemic adjustments of investigated systems to improve value co-creation in digital servitized contexts. Thus, the key dimensions represented a theoretically and empirically grounded categorization. Figure 2 shows the entire data structure resulting from the data analysis. This step of the data analysis was conducted conjointly by the authors, who thoroughly discussed the data structure, assessing for further linkages between key dimensions, second-order themes and first-order categories across cases (Table 2). Case comparison allowed us to further refine our data structure and create an overall framework (Figure 3) to explain how the complex sociotechnical processes were handled to generate innovative digitalized outcomes.

\section{Findings}

The following Sections 4.1 and 4.2 provide case descriptions that explain each of the key dimensions as core pillars of the transition to digital servitization. This is also supported by Table 2 that provides a summarized overview of the representative quotes for each case company.

\subsection{Alpha}

\subsubsection{Setting the condition for value co-creation}

In the predigital servitization state of Alpha, a product-centric logic dominated due to inefficiencies in the management of service activities. This logic negatively affected the overall quality of the service delivery and the opportunities for tailoring solutions offered to business clients, such as mass-market retailers and hotel, restaurant and catering $(\mathrm{HoReCa})$ players. In particular, the absence of real-time information led to front-/back-end misalignment within the company's marketing and sales department, compromising waterfall-like relationships with the network of industrial clients. In fact, as the sales director declared: "an Alpha's weakness concerned an on-off coordination between frontline and backline staff whose informative exchange about purchase orders was email-based." This decoupling was based on an organizational structure in which sub-systems of the front and back ends operated fuzzily: they separately collected, prioritized and stored customer information. Thus, Alpha failed to deeply know its customers and missed opportunities to capture and add value to the knowledge stock within its ecosystem. The relational context was negatively affected: Alpha dealt with inefficient activities of inbound and outbound logistics (i.e. backline staff), while mass-market retailers and $\mathrm{HoReCa}$ clients faced service failures in terms of the product type, quantity received and delivery delays, thus increasing the likelihood that they would switch to other, more effective suppliers. Contextually, failure to plan service travel and optimize load capacity damaged service logistic providers that reacted by increasing their transport costs.

The lack of tightly coupled linkages implied the need for Alpha to move toward a digital servitization state. This shift was gradual and encouraged by the firm belonging to international industry organizations (e.g. trade-specific associations and manufacturing associations).

Alpha started to blur its boundaries by cooperating with technology service providers in the joint development of an ecommerce platform to develop customized offerings. As tool manager declared: "I think we need to work closer with the technological providers since our customers ask for tailored digital solutions." The e-commerce platform was based on an integrated system allowing the front-/back-end coupling and front-end mistakes' reduction because business clients inserted order data by accessing their user areas. At the same time, various interfaces integrated into the functionality of the platform were available to the back end, improving the integration of resources and the smoothing of activities. Furthermore, business clients were more actively engaged in purchase activity, contributing to solving the problem of a nonfluid informative exchange. Thus, a diffuse creation of value was achieved through the digital solution shared among actors: Alpha addressed internal inefficiencies and B2B clients overcame service failures.

\subsubsection{Systemic and systematic combining}

Alpha gradually invested further in the e-commerce platform with the aim "to systematically launch new services and functionalities based on the platform in the near future" as customer solution manager stated. An instant messaging tool was added to allow real-time interactions between Alpha and its

Figure 2 Data structure and coding process

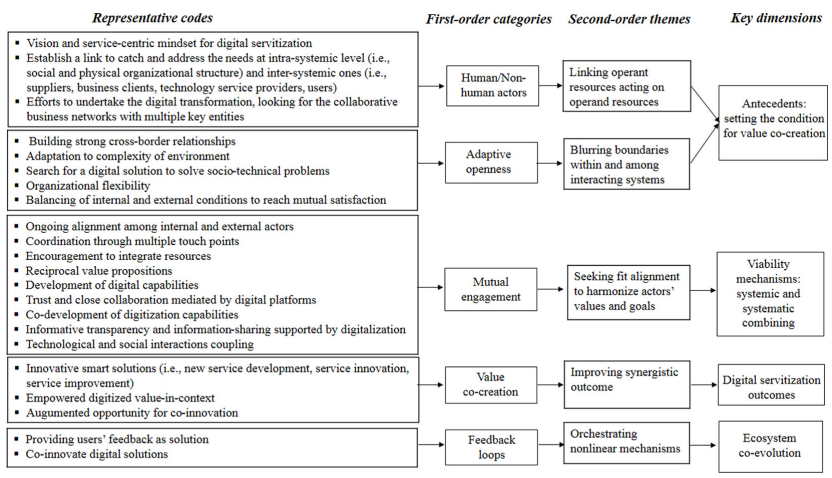

Source: Authors' elaboration 


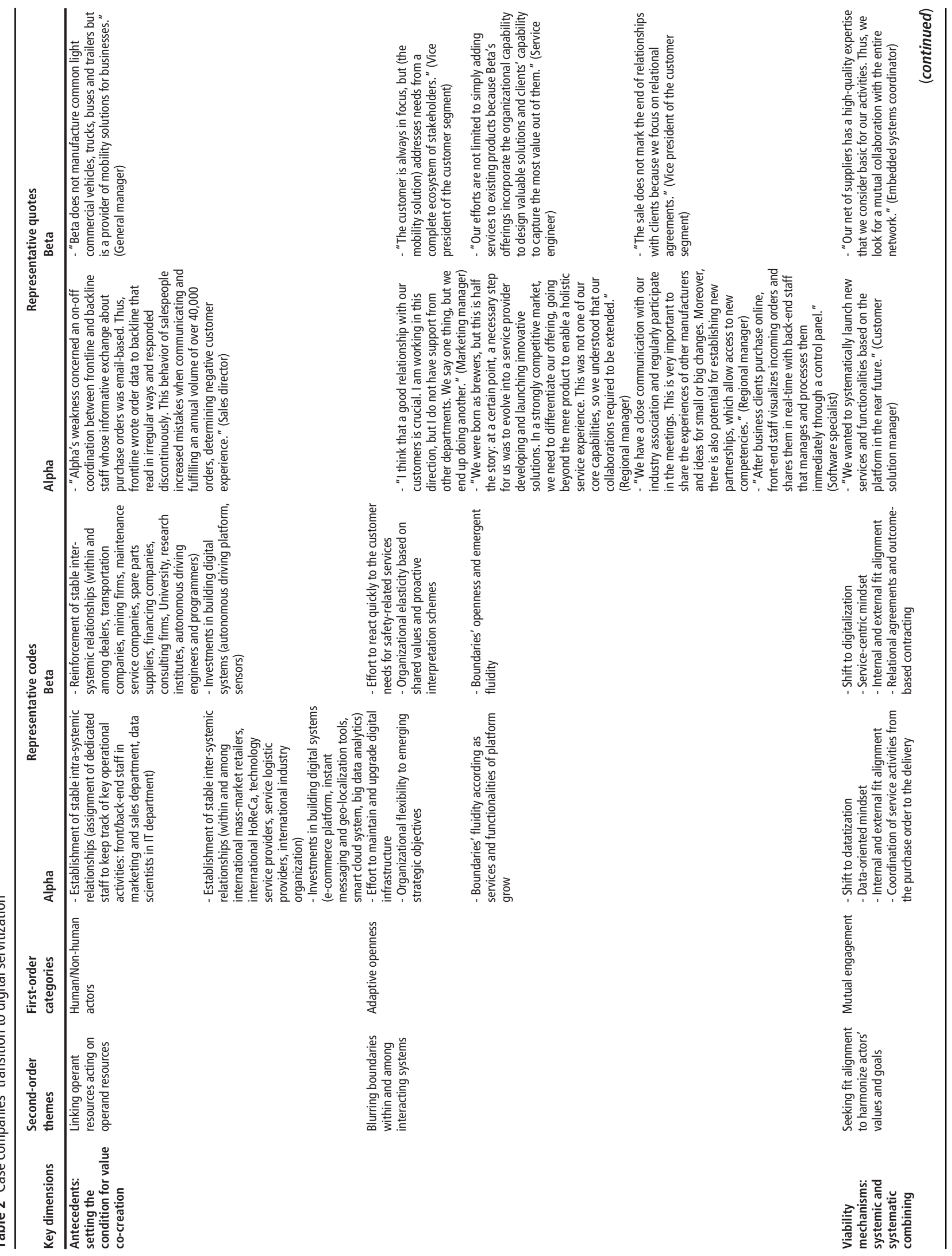




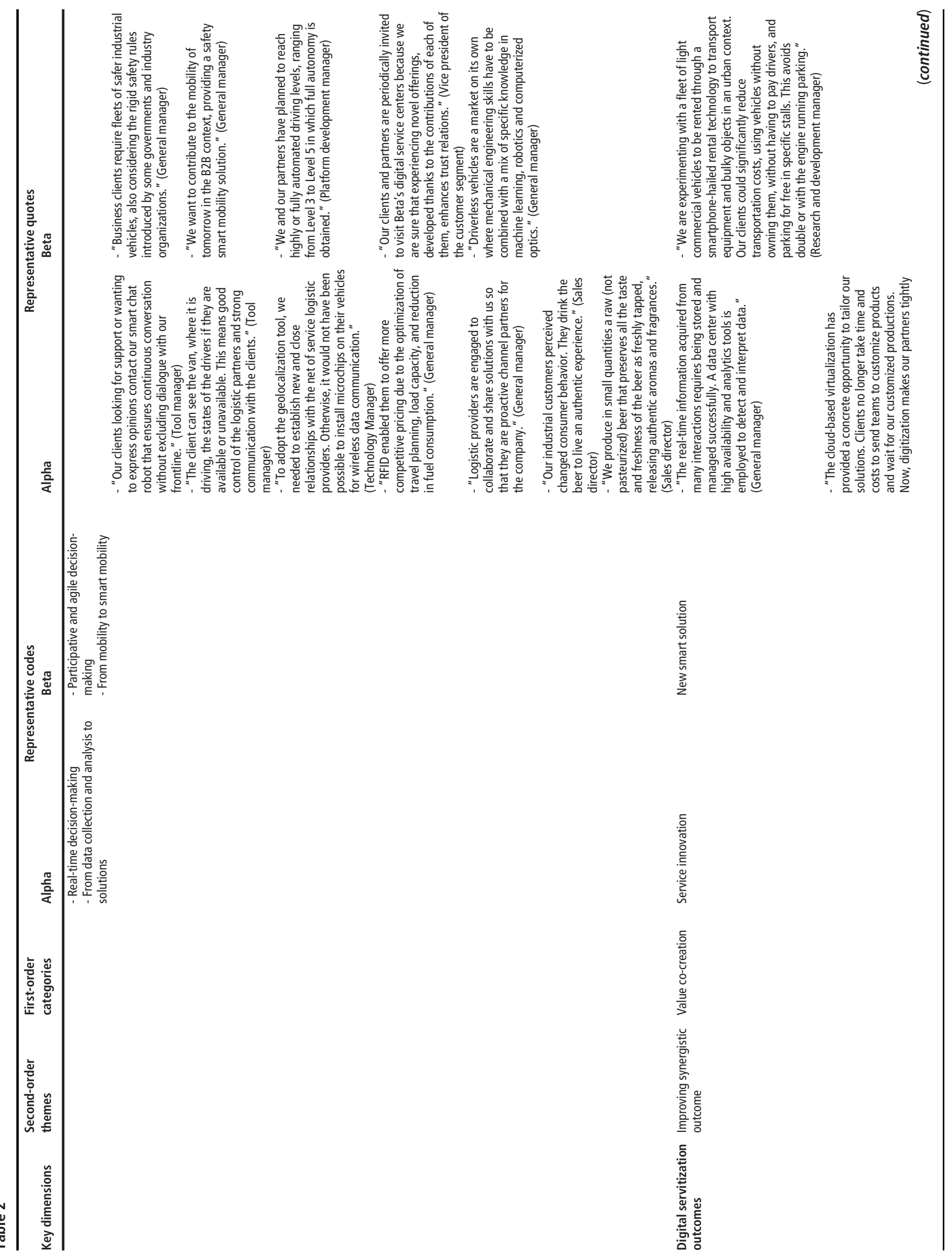




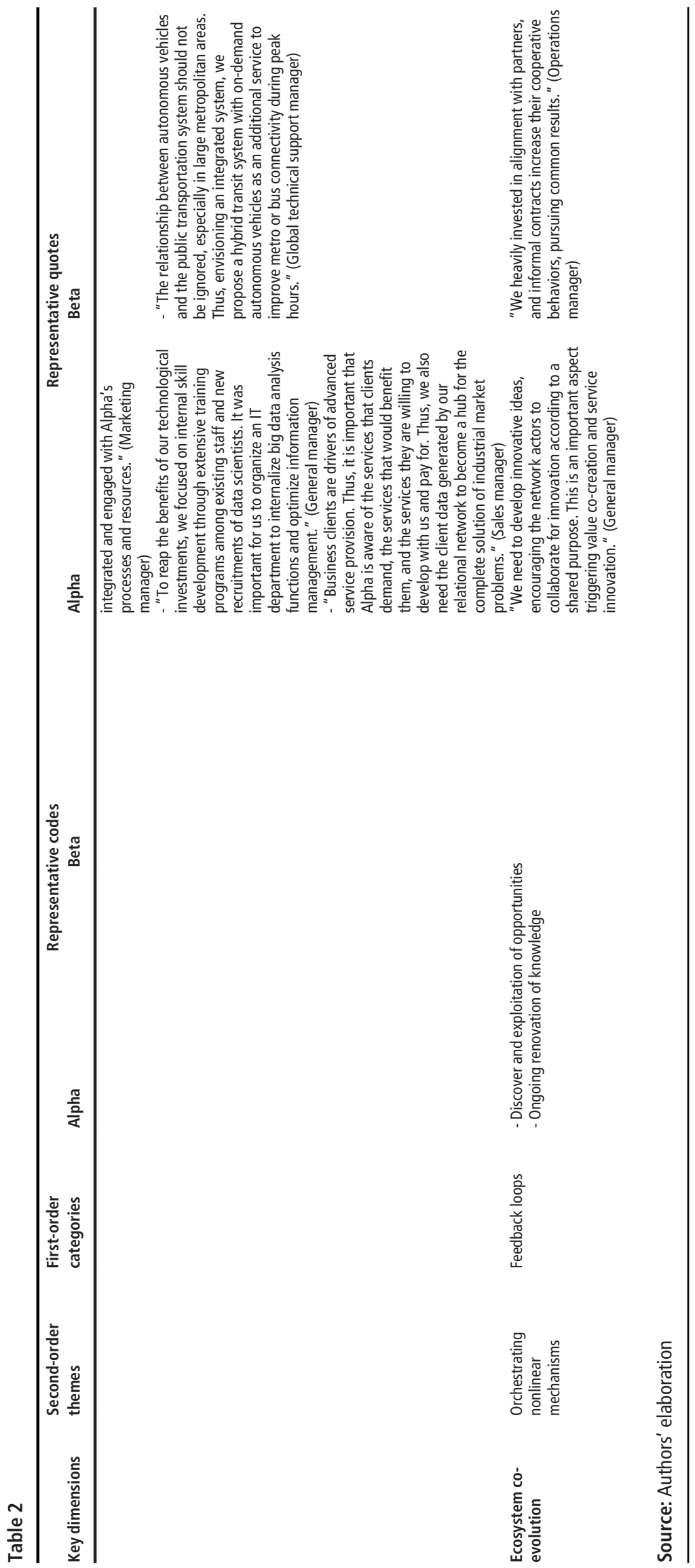


Figure 3 Revised digital servitization framework through the empirical application
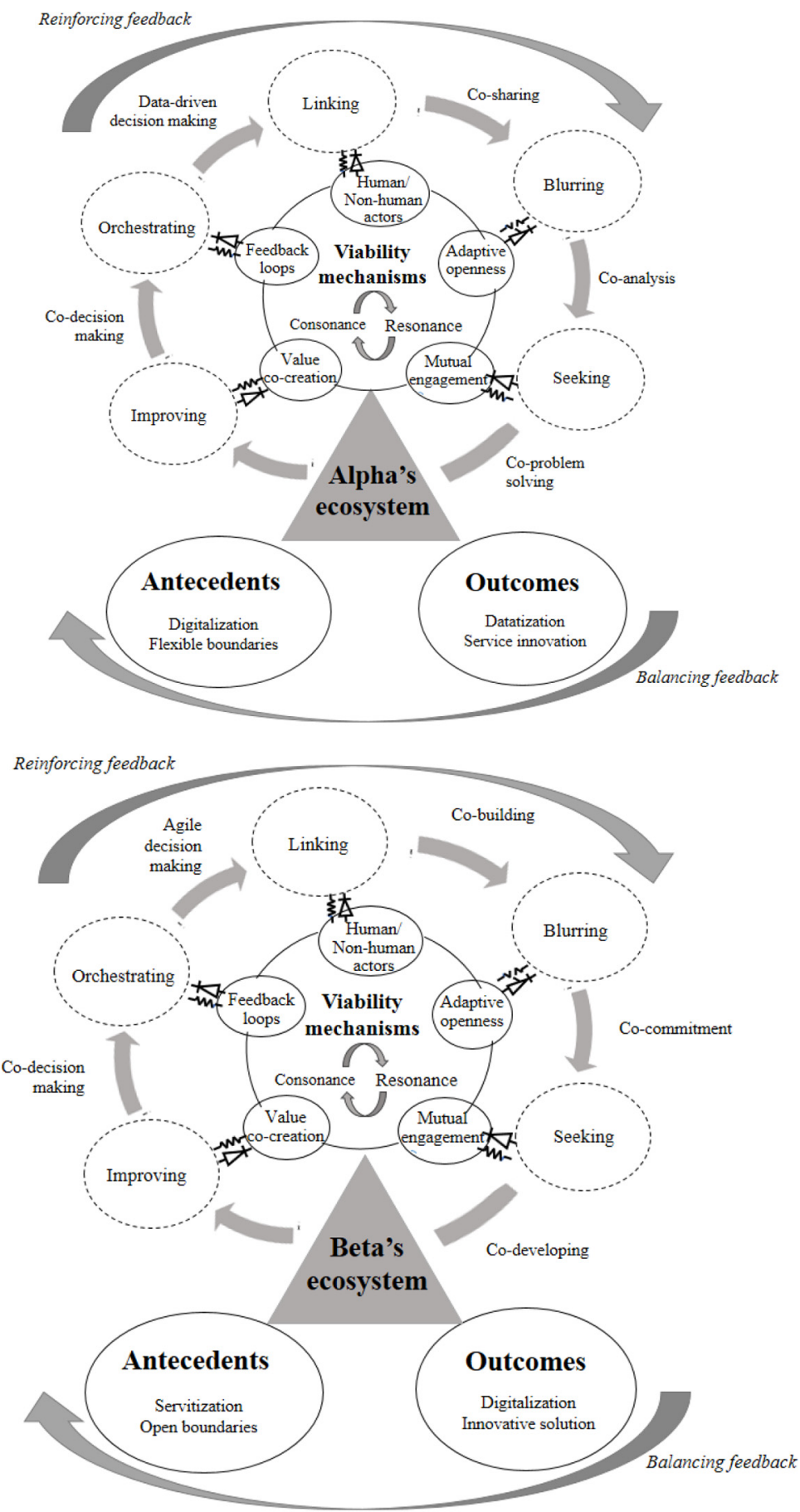

Source: Authors' elaboration

business clients, integrating the possibility of posting comments on the e-commerce platform. By doing so, Alpha improved its response time to the requests of geographically dispersed customers. Additionally, a geospatial tool was implemented to provide advanced delivery services, allowing clients to exactly localize their orders, visualizing on maps the service logistic providers involved in the delivery through radio frequency identification (RFID) technology. Consequently, Alpha held many face-to-face meetings with service logistic providers. Initially, these providers were hesitant about the RFID technology; then, they became aligned in a shared value proposition in which mutual increase in revenue and upgrading of capabilities were achieved through a risk-sharing agreement. In particular, Alpha was able to achieve both customization and 
coupled customer interactions; moreover, the digital solution that captured information on products in real-time allowed it to manage an efficient flow of returns (i.e. reverse logistics) owing to collaboration with its service logistic partners.

On the logistic providers' side, RFID solution has allowed optimizing travel planning, load capacity and reduction in fuel consumption, also providing prices that were more competitive. Moreover, the logistic partners took advantage of the opportunity to use RFID as a new solution offering.

The e-commerce platform went beyond its exclusively commercial aim to become a web-based interactional architecture: in fact, its increasing use generated seamless and multidirectional communication flows because the actors coshared immediate, simultaneous and continuous access to the platform and its tools. This interaction platform created a virtual connection between Alpha and other actors, enhancing the experiences of "partnering" aimed at seeking mutual alignment. For instance, owing to continuous informative exchanges via the platform, Alpha soon realized that its Spanish customers wanted to move away from mainstream beer sales. For this reason, Alpha was prepared to align the offering with the needs of its clients, investing in craft beer as a new product line.

\subsubsection{Digital servitization outcomes}

The interactional platform allowed the collection of data from many different sources. This proliferation of data led to the need for a centralized solution that combined and analyzed them to create advanced services. By collaborating with a platform provider, Alpha developed a cyber-physical systemrelated solution, such as a cloud-based big data analytics tool, that enables the actors' network to co-analyze data and be alerted to risks in terms of monitoring product lines, tracing loads, and purchasing raw materials and packaging. In this way, Alpha and its partners were jointly able to discover and exploit opportunities for service improvement and new service development, paving the way for closer relationships.

At the same time, Alpha adopted additional customer relationship management analytics devoted to transforming customer data into insight that provided grounds for market intelligence. This further evolution toward digital servitization implied that all business processes were oriented toward customer service as a result of a customer-centric logic and entailed the enrichment of data analytics skills in the whole organization, as well as adapting sub-systems to include an information technology department. This organizational stretch beyond manufacturing skills was rewarded by endless opportunities provided by the correct analysis and integration of data from the network of relationships. For instance, Alpha could leverage collaborative decision-making with reduced complexity and decision-making time because an improved understanding of business clients' needs fostered the optimization of business processes and overall service delivery. Moreover, the use of customer data increased effectiveness in recognizing and addressing customers' problems and translating their needs into new advanced service solutions in an efficient, tailored and collaborative way. Thus, service quality improved, and customer satisfaction and loyalty were positively affected.

\subsection{Ecosystem co-evolution}

Developing technologies around software compatible with hardware of the actors' network, Alpha's vision gradually oriented the strategic choices of other actors by leveraging and improving the ongoing process of resource integration that leads to knowledgeable actors and fosters overall service interactions and related outcomes.

Overall, through a constant process of adaptation, Alpha demonstrated proficiency and credibility in orchestrating value co-creation activities and their related processes within its network of relationships, paving the way for seamless knowledge endowment and ongoing digital service innovation.

\subsection{Beta}

\subsubsection{Setting the condition for value co-creation}

In Beta's pre-digital servitization state, a service-centric logic dominated as a vision that inspired the entire organization. The general manager confirmed, "Beta does not manufacture common light commercial vehicles, trucks, buses and trailers but is a provider of mobility solutions for businesses," such as dealers, service logistic providers, transportation companies and mining firms.

Following this vision, Beta put service at the basis of its competitive strategy aimed at differentiating its offerings and adapting to heterogeneous customer needs.

The product-related services portfolio consisted of after-sales services aimed at increasing Beta's revenue and customer value during the entire life cycle of the vehicles. They comprised maintenance contracts, financing schemes and consulting services customized and offered as packages that linked services together. To increase the interaction intensity and number of touchpoints with customers, Beta introduced offerings such as monitoring diagnostics and corporate credit-card services. In addition, the company's portfolio comprised use-oriented services - such as leasing, renting and sharing - which required the active involvement of customers to develop and deliver tailored solutions and satisfy on-demand requests.

Therefore, Beta designed an integrated product-service bundle in which the personnel, facilities, relational skills and capabilities of both company and customers were embedded and shared. Moreover, additional advanced services allowed Beta to increase customer engagement since service was embedded in customer relational processes. According to this logic, the company worked in close collaboration with its clients to achieve mutual business goals, paving the way for reciprocal long-term relationships based on trust. Such service centricity was achieved by organizing for mutual dependency and a shared agenda through common value creation logic adopted at each stage of the value chain owing to blurred boundaries. The effective delivery of integrated product-service solutions required both intra- and inter-systemic integration by merging operand and operant resources. Beta invested in the combination of multiple ICT-based systems (i.e. a machineuser interface) to achieve sufficient modularization and connectivity. This led to the creation of synergies among subsystems and improved collaborations among the service teams that tracked the connected products and the service engineers who performed inspections, repairs and maintenance. Moreover, Beta maintained stable connections with the suppliers of machines, equipment applications, professional 
facilities, maintenance systems and spare parts supply systems, as well as financing companies and consulting firms.

\subsubsection{Systemic and systematic combining}

Beta quickly embarked on an important shift toward a digitalization path due to the introduction of global safety regulations to avoid industry accidents.

Beta seized this business opportunity to migrate toward digital services. The achievement of this opportunity affected the reorganization of the overall value system, depending on the objectives and activities of actors from other ecosystems.

Specifically, Beta looked for synergies with technology service providers, machine suppliers, and research institutes by establishing a "talent network" to integrate internal and external knowledge resources and increase open collaborations in the autonomous driving area. As a result, the "talent network" co-developed a platform for automated driving, allowing industrial vehicles to accomplish complex tasks ranging from driving to loading and unloading raw materials. Vehicle smartness was achieved through innovative technologies (i.e. advanced video perception and highdefinition mapping, highly performant sensors and artificial intelligence) that offered the highest safety and versatility at the production sites. The platform included IoT solutions that allowed smart vehicles to communicate in real-time with each other (vehicle-to-vehicle communication) and with the central infrastructure (vehicle-to-infrastructure communication).

The co-development platform was based on the company's effort to seek external fit alignment to preserve coupled B2B relationships. Initially, many negotiations were necessary to achieve the co-commitment of all partners to goal achievement. As the general manager stated: "We are sure that regular meetings, consultations, workshops and brainstorming foster iterative exchanges bringing to an ongoing involvement in common rules and values." Beta increased its attention to cobuilding trust among partners and followed clear cooperation rules to ensure smooth collaborations, manage openness and sustain innovations. In this regard, it developed a partner program to provide a comprehensive set of benefits (e.g. sales and technical training, application development tools, technical support, marketing resources, legal support and business development funds). External fit alignment also enabled it to involve new actors, such as universities, research centers, autonomous driving engineers and programmers, with and from whom to co-build capabilities and learn continuously.

\subsubsection{Digital servitization outcomes}

Collaborative development of the platform improved benefits and created new value for the actors involved. Beta improved customer experience because the platform architecture and functions were co-designed with other actors, and its modular nature allowed high customization and operational adaptiveness to multi-actor contexts of use. Moreover, the platform allowed Beta to plan access to an emerging market of van sharing, expanding its reach in the field of pay-perkilometer vehicle rental services. This could mean not only market innovation but also environmental sustainability in terms of the reduction of both traffic and air pollution.

At the same time, the platform reinforced the capability of industrial clients to improve their productivity because the smart vehicles performed better than human drivers in terms of perception (e.g. no blind spots), decision-making (e.g. more accurate planning of complex driving maneuvers such as parallel parking) and execution (e.g. faster and more precise control of steering, brakes and acceleration). Moreover, the platform improved the reputation of Beta's clients as sustainable companies in the eyes of their customers. In fact, switching safety-critical tasks from humans to machines demonstrated social sustainability efforts to reduce job accidents and fatalities and promote easier job accessibility for people unable to drive.

\subsubsection{Ecosystem co-evolution}

In the wide reconfiguration of the ecosystem, Beta acted as a knowledge-intensive solution by taking responsibility for coordinating and integrating old and new actors and shaping innovative resources, co-innovating new technical solutions. Outcome-based contracting as relevant coordination mechanisms has allowed orchestrating tighter multi-actor coupling. Finally, a mutual alignment toward a shared value proposition was the key for participative and agile decisionmaking in which all actors actively engaged, contributing to Beta's strategic direction.

New business opportunities emerged within the effects of service ecosystem digitization because the platform was able to enhance regulatory and systematic debate and users' feedback in relation to testing licenses, accidents between smart and traditional vehicles, and smart vehicle use on public roads. Owing to the most advanced machine-learning technologies, the platform can derive real-time information, make ad hoc recommendations and stimulate creative thinking to effectively address future needs.

In this regard, the platform is co-designed to represent a revolutionary future for urban mobility through the possibilities of hybridizing autonomous vehicles and public transportation, including improvements in the intermodality and individualization of the transit service.

\section{Discussion}

The cross-case analysis allows us to explore how manufacturers manage digital servitization to create value in industrial markets. To this end, the analysis of actors, activities and digital tools allows us to identify emergent resource exchanges, thereby exploring how they are dynamically combined to generate innovative outcomes. The findings show that both case companies strategically managed the sociotechnical processes of digitalization to enhance their competitiveness. Regardless, differences in service orientation delineated dissimilar journeys toward digital servitization. This finding is in line with a system principle of equifinality referring to a property of open systems reaching the same end state of the structure even when starting from different conditions and/or taking different paths (Barile et al., 2012a). Overall, both case companies' journeys embraced digital servitization, despite Beta shaping a more viable digital ecosystem, harmonically combining service centricity and the ability to cope with contextual variety. This finding is in line with both VSA's constructivist view and the influence of servitization maturity on digitalization level (Polova and Thomas, 2020).

By interpreting the iterative and non-linearity of the framework proposed in the light of the empirical findings, the 
integrated interplay of the key dimensions is discussed below (Figure 3).

Alpha gradually moved from digitalization to servitization due to the lack of tightly coupled linkages among and between front- and back-end staff and industrial clients initially viewed as exogenous recipients of a company's value proposition. The lack of internal (unskilled people) and external consonance led to the absence of real-time information exchanges, creating knowledge silos that caused inefficiencies in both human resource management and customer relationships. Thus, the ecommerce platform acted as an accelerator of market knowledge because it fostered the smoothing of informative exchanges, also disseminating market intelligence to different departments and fostering synergistic activities. In contrast, Beta quickly moved from servitization to digitalization arising from customer-centricity expressed by integrated productservice bundles and active investment in stable relationships, mediated by technological tools (i.e. from basic ICT-based systems that facilitated production processes and service operations to multiple ICT-based systems) and close collaboration on the overall value system. Thus, a crucial antecedent of digital servitization lies in the relational capability of organizing relationships, of different natures and extents, connecting relevant actors (supra- and sub-systems) and aligning activities and related processes to improve mutual understanding. This leads to different opportunities for leveraging digitalization, also affecting system boundaries. Alpha showed flexible boundaries to foster the establishment of new relationships according to the incremental use of a wider range of digital technologies to improve customers' knowledge. Boundary flexibility moved at the same pace as the flexibility of the system through adaptive behavior consisting of back- and front-end optimization. Likewise, Beta showed open boundaries characterized by emergent fluidity due to the selection and ongoing involvement of new actors (i.e. universities, research centers and scientists) with whom the company integrated and created new external market knowledge from extended partnerships mediated by platforms that enabled modularization and connectivity (Lusch and Nambisan, 2015).

The implementation of multiple digital tools allowed more open exchange of information between the involved actors and made stronger operational linkages, as well as data transparency and analysis, sustaining thereby an alignment of values and incentives to foster value co-creation. Hence, an operational and strategic alignment was achieved through the viability mechanisms that worked as relational strategies to ensure structural and systemic stability. In particular, consonance fostered the coordination of the relationships across different functions to maximize contribution coming from actor-network, paying the way to the creation of synergies and avoiding possible conflicts. Resonance reinforced the coordination and harmonization of the interactions through collaboration and cooperation aimed to synchronize shared objectives and mutual engagement between involved actors. Consequently, the synergistic exchange of resources produced the enhancement of the skills and the provision of new knowledge for the actors involved. Thus, consonance and resonance are homeostat mechanisms that ensure and allow the system viability (von Bertalanffy, 1968). Acting as variety attenuators, they absorbed variety by allowing the system to align its tangible and intangible resources with complementary resources provided by the actor-network. Thus, the viability of the ecosystem was reinforced. For instance, the provision of an advanced delivery services to Alpha's business clients was possible because of the close collaboration of service logistic providers willing to the mutual usage of RFID technology and sharing of information.

The combined effect of the viability mechanisms allowed dynamic adjustments actualized in co-created activities.

By adapting its ecosystem, Alpha shaped the service value network through the following co-created activities:

- co-problem solving, obtained through resource integration by matching managerial and technical capabilities with the identification of specific customer performance improvements and operational requirements;

- co-sharing by integrating data storage and data sharing with jointly discussed and agreed-upon greater experiences and value innovations, matching the expertise of the suppliers' network with the experience of the customers' network to reduce technical and social asymmetries and carrying out a set of collaborative rules; and

- co-analyzing, consisting of the integration of digital capabilities by technology experts and suppliers to extract information from which emergences are constantly detected in real-time, and thereby new value is obtained through big data analytics to translate customer data into data forecasts.

In contrast, strong service centricity pushed Beta to reconfigure its ecosystem, establishing cross-sectoral partnerships, allocating resources on joint activities and nurturing mutual value propositions through rule clarity for long-term cooperation. Thus, the following co-created activities were achieved:

- co-developing, obtained through resource integration by generating and suggesting a joint elaboration of new cocreated solutions, scanning new technological frontiers (i.e. AI) and advanced applications (i.e. data models and analytical methods), and bringing together ideas, designs and talent from internal and external ecosystems;

- co-committing by integrating and optimizing cooperation management practices, including shared rules and standards, to jointly craft value propositions and jointly specify value perspectives; and

- co-building, consisting of new capabilities that are synergistically recombined in new knowledge, cooperating with scientific and technological partners to increase technical, managerial and relational capabilities, together with the enhancement of specific digital capabilities (i.e. intelligence, connective and analytic functions) toward new co-created customer-centric offerings.

The synergistic combining of the co-created activities affects an innovative mindset, institutionalized to actualize an ongoing value creation, involving the overall decision-making process.

In Alpha, data-driven decision-making allowed it to extract significant information and meanings from data empowering knowledge sharing. First, the provision of additional functions 
of the offering by means of a wider range of digital tools (i.e. instant messaging and geolocalization tools integrated into the e-commerce platform) allowed seamless access to and sharing of information through interaction-in-use (Vargo and Lusch, 2011) and allowed it to implement integrated strategies with clients, service logistic providers, etc. Second, a cloud-based big data analytics tool sustained by a technical and analytics skills pool allowed it to store, process and extract real-time data, unlocking value from them to co-create new value propositions. This corroborates the proposition that data centricity (Svahn et al., 2017), which is the synchronization of digitization, connectivity and data analytics, increases opportunities for value co-creation (Martín-Peña et al., 2018).

In Beta, agile decision-making allowed digitalization to be obtained through the development of digital co-capabilities. Agility, as flexibility and continuous realignment to changes (Weber and Tarba, 2014; Bustinza et al., 2018), is crucial for sustaining value co-creation for the advancement of new integrated solutions. Agility allows a timely response to the need for scalability and speed in rapidly changing environments where technologies' life cycles are short (Tronvoll et al., 2020). Then, we can advance that the co-commitment to decisions acts as glue that enables swift and decisive interorganizational and business reconfigurations. Co-commitment affects the overall value architecture at the identity level due to the full inclusiveness of multiple actors as partners and leads to generate not only smart solutions but also new markets.

Consequently, and in line with the digital servitization outcomes key dimension, outcomes achieved by the two case companies are different due to the distinct degree to which decision-making copes with contextual variety and imagines protovisions (Nenonen and Storbacka, 2020). In particular, the datatization pursued by Alpha led to ongoing service innovation and data-intensive processes and supported and enhanced the quality of decision-making. The digitization pursued by Beta led to co-innovative smart service solutions for new emerging needs (i.e. cybersecurity digital services). Matching industrial, scientific, technical and academic expertise, Beta is acknowledged to have developed an institutionalized knowledge-intensive solution.

Ongoing innovative digitalized outcomes can be promoted over time owing to feedback loops to foster the constant diffusion and rearrangement of the new knowledge generated within a systematic and iterative process oriented toward discovering and exploiting new opportunities for value creation and co-evolution. This process requires the appropriate orchestration of cycles from which feedback loops arise. Thus, in analyzing the two ecosystems as a whole, we advance the existence of transformational mechanisms named reinforcing and balancing feedback loops as nonlinear and iterative mechanisms that allow outcome achievement and, ultimately, ecosystem viability and co-evolution over time (Peters et al., 2020). More specifically, reinforcing feedback is a perceptive mechanism based on the capability to discover and exploit untapped opportunities. It requires the orchestration of comonitoring activity and related processes by multiple short planning and execution cycles based on user feedback, as well as regular meetings and follow-ups among actors to gain a fluid understanding of their resources and interests (Paluch et al., 2020). Instead, balancing feedback is a responsive mechanism acting based on the orchestration of co-learning activity and related processes that renovate knowledge in a continuous cycle of sensing, responding and adapting. In doing so, resourcefulness increases since each knowledge resource become able to support other knowledge resources in achieving innovative outcomes (Koskela-Huotari and Vargo, 2016). An effective and harmonic orchestration of cycles from which feedback loops arise sustains an update of the iterative process of value co-creation since the outcomes obtained in a given time represent improved antecedents that reinforce the re-start of the cycle. Thus, the human-mediated integration of digital resources, platforms and tools turns into strategic assets actualizing improved value co-creation that sustain an enduring digital innovation. Hence, viability and co-evolution of the entire ecosystem are fostered over time.

\section{Implications, limitations and further research}

The paper contributes to enriching and extending the emerging body of literature on digital servitization (Tronvoll et al., 2020; Kamalaldin et al., 2020), thus stimulating further scholarly work in value co-creation implementation and simultaneously providing guidelines to facilitate the attainment of value cocreation in digitized B2B markets. The work advances a theoretically grounded, empirically informed framework to detect transformational mechanisms to manage value cocreation in digitally servitized contexts, contributing to ecosystem viability and co-evolution in the long run. Cocreated activities are identified, and five higher-order categories are conceptualized to make sense of digital servitization in line with a systems view and a systematic process based on a transformative attitude toward digital servitization.

Therefore, the study can be considered a further step in extending knowledge on digital innovation emergence in B2B manufacturing systems by categorizing different viability mechanisms and proposing transformational ones that foster innovation. Thus, it confirms the disruptive aspect of digital servitization that leads to significant transformations in how integrated solutions are designed, produced and delivered, involving changes in strategies, activities and the value network (Vendrell-Herrero et al., 2018). In addition, the study encourages the consolidation of a research orientation that expands its scope to the systematic integration of investigating interdependencies among actors by detecting specific cocreated activities. Thus, it provides additional research on the micro-foundations of value co-creation (Storbacka et al., 2016).

At the same time, the paper offers direct implications for managers from the manufacturing industry who drive digital servitization initiatives in $\mathrm{B} 2 \mathrm{~B}$ markets. The practical stance lies in the identification of specific digital servitized journeys that research findings indicate are value-driven and partnershipfocused. Thus, organizations that plan similar endeavors can benefit from this study and more effectively and efficiently manage the necessary transformational shifts, choosing more suitable transition routes between datatization supporting servitization and servitization supporting digitalization. Consequently, managers can collect insights into the proper combination of technology and human interactions to manage strategic value co-creation that can allow, in turn, the 
harmonization of complex innovation processes. Managerial implications also underlie the conceptual framework. First, executives can rely on practical mechanisms when designing innovation projects that are consistent with digital servitization plans. For instance, the co-monitoring required by reinforcing feedback can be implemented through smart decision support systems that enhance the capability to collaboratively discover and exploit untapped opportunities. Additionally, the colearning required to balance feedback can be achieved through strategies based on the valorization of the multiple contributions of ongoing upskilled actors within the process of value generation and inspired by survival in the long run. Relying on practical mechanisms would lead to the definition of managerial models that highlight digital servitization with greater potential for companies according to contingency factors, such as industry, company size and supply chain position. Second, our framework represents a valuable solution for practitioners and industry groups seeking a more contemporary managerial framework that, by being receptive to the ecosystem view, enables practitioners to see beyond the firm boundaries and perceive multiple tiers of suppliers, customers, and users that directly and indirectly provide information and resource flows. This change in perspective may represent a relevant contribution to $\mathrm{B} 2 \mathrm{~B}$ industrial management, helping understand decision-making in conditions of complexity. In particular, the set of processual dynamics underlying specific co-created activities can be amplified or reduced according to the contextual circumstances, supporting decision-making to better adapt to internal and external contextual variety.

Although the study offers valuable contributions, some limitations must also be recognized, suggesting directions for future work. First, the adoption of the case-study methodology, scarcity of case companies and low number of interviews do not allow a consistent generalization of the results. Regardless, the paper proposes exploratory research that is a first qualitative step toward addressing future quantitative studies on a higher number of firms. Second, our attention is focused on manufacturing, although the literature has started to investigate the phenomenon in other industries. Thus, future studies can explore servitization beyond the boundaries of manufacturers to compare results obtained in other organizational contexts. Third, all the interviews were conducted in the two focal firms. In the future, respondents from both sides of the interactions (i.e. both the customer and the provider view) could be involved to provide validation and contextual richness for the analysis, enabling a deeper understanding of the phenomenon. Moreover, future studies could deepen the longitudinal nature of digital servitization, extending the search for how the transformational efforts of manufacturers develop over time in accordance with changing circumstances and conditions. Finally, future research could adopt a system dynamics lens, which may offer interesting insights into the narrative of digital servitization.

\section{References}

Akaka, M.A., Vargo, S.L. and Lusch, R.F. (2012), "An exploration of networks in value cocreation: a serviceecosystems view", Review of Marketing Research, Vol. 9, pp. 13-50.
Barile, S. (2009), Management Sistemico Vitale, Giappichelli, Torino.

Barile, S. and Saviano, M. (2013), "An introduction to a value co-creation model, viability, syntropy and resonance in dyadic interaction", Syntropy, Vol. 2 No. 2, pp. 69-89.

Barile, S. and Polese, F. (2010), "Smart service systems and viable service systems: applying systems theory to service science", Service Science, Vol. 2 Nos 1/2, pp. 21-40.

Barile, S., Pels, J., Polese, F. and Saviano, M. (2012a), "An introduction to the viable systems approach and its contribution to marketing", fournal of Business Market Management, Vol. 5 No. 2, pp. 54-78.

Barile, S., Saviano, M., Polese, F. and Di Nauta, P. (2012b), "Reflections on service systems boundaries: a viable systems perspective. The case of the London borough of Sutton", European Management fournal, Vol. 23 No. 4, pp. 161-180.

Barile, S., Lusch, R., Reynoso, J., Saviano, M. and Spohrer, J. (2016), "Systems, networks, and ecosystems in service research", Fournal of Service Management, Vol. 27 No. 4, pp. 652-674.

Barile, S., Polese, F., Calabrese, M., Iandolo, F. and Carrubbo, L. (2013), "A theoretical framework for measuring value creation based on viable systems approach (VSA)", in Barile, S. (Ed.), Contributions to Theoretical and Practical Advances in Management, Viable Systems Approach, ARACNE Editrice, Roma, pp. 61-94.

Batista, L., Davis-Poynter, S., Ng, I. and Maull, R. (2017), "Servitization through outcome-based contract: a systems perspective from the defence industry", International fournal of Production Economics, Vol. 192, pp. 133-143.

Braun, V. and Clarke, V. (2006), "Using thematic analysis in psychology", Qualitative Research in Psychology, Vol. 3 No. 2, pp. 77-101.

Breidbach, C.F. and Maglio, P.P. (2016), “Technologyenabled value co-creation: an empirical analysis of actors, resources, and practices", Industrial Marketing Management, Vol. 56, pp. 73-85.

Bustinza, O.F., Gomes, E., Vendrell-Herrero, F. and Tarba, S. Y. (2018), "An organizational change framework for digital servitization: evidence from the Veneto region", Strategic Change, Vol. 27 No. 2, pp. 111-119.

Ciasullo, M.V. (2018), Service Innovation in (Eco)System View. Towards a Circular Path of co-Innovation, Giappichelli Editore, Torino, Italy, pp. 1-164, ISBN/EAN 978-88-9211594-1.

Coreynen, W., Matthyssens, P. and Van Bockhaven, W. (2017), "Boosting servitization through digitization: pathways and dynamic resource configurations for manufacturers", Industrial Marketing Management, Vol. 60, pp. 42-53.

Dubois, A. and Gadde, L.E. (2002), "Systematic combining: an abductive approach to case research", fournal of Business Research, Vol. 55 No. 7, pp. 553-560.

Dubois, A. and Gadde, L.E. (2014), "'Systematic combining"”a decade later”, Fournal of Business Research, Vol. 67 No. 6, pp. 1277-1284.

Eisenhardt, K.M. and Graebner, M.E. (2007), "Theory building from cases: opportunities and challenges", Academy of Management fournal, Vol. 50 No. 1, pp. 25-32. 
Galvagno, M. and Dalli, D. (2014), "Theory of value cocreation: a systematic literature review", Managing Service Quality, Vol. 24 No. 6, pp. 643-683.

Gebauer, H., Fleisch, E., Lamprecht, C. and Wortmann, F. (2020), "Growth paths for overcoming the digitization paradox", Business Horizons, Vol. 63 No. 3, pp. 313-323.

Ghobakhloo, M. (2018), "The future of manufacturing industry: a strategic roadmap toward industry 4.0 ", fournal of Manufacturing Technology Management, Vol. 29 No. 6, pp. 910-936.

Gioia, D.A., Corley, K.G. and Hamilton, A.L. (2013), "Seeking qualitative rigor in inductive research: notes on the Gioia methodology", Organizational Research Methods, Vol. 16 No. 1, pp. 15-31.

Goffin, K., Åhlström, P., Bianchi, M. and Richtnér, A. (2019), "State-of-the-art: the quality of case study research in innovation management", Fournal of Product Innovation Management, Vol. 36 No. 5, pp. 586-615.

Golinelli, G.M. (2010), Viable Systems Approach (VSA). Governing Business Dynamics, Cedam, Padua, Italy.

Grandinetti, R., Ciasullo, M.V., Paiola, M. and Schiavone, F. (2020), "Fourth industrial revolution, digital servitization and relationship quality in Italian B2B manufacturing firms. An exploratory study", The TQM fournal, Vol. 32 No. 4, pp. 647-671.

Gummesson, E. (2017), Case Theory in Business and Management: Reinventing Case Study Research, Sage: New York, NY.

Gummesson, E. and Polese, F. (2009), "B2B is not an island", Fournal of Business E Industrial Marketing, Vol. 24 Nos 5/6, pp. 337-350.

Gummesson, E., Mele, C., Barile, S. and Polese, F. (2010), "Linking the viable system and many to many network approaches to service dominant logic and service science", International fournal of Quality and Service Sciences, Vol. 2 No. 1, pp. 23-42.

Hakanen, T., Helander, N. and Valkokari, K. (2017), "Servitization in global business-to-business distribution: the Central activities of manufacturers", Industrial Marketing Management, Vol. 63, pp. 167-178.

Kaartemo, V., Jaakkola, E. and Alexander, M. (2019), "Roles of technology in actor engagement", 16th International Research Symposium on Advancing Service Research and Practice, Fune, pp. 1-11.

Kamalaldin, A., Linde, L., Sjödin, D. and Parida, V. (2020), "Transforming provider-customer relationships in digital servitization: a relational view on digitization", Industrial Marketing Management, Vol. 89, pp. 1-20.forthcoming.

Kohtamäki, M., Parida, V., Patel, P.C. and Gebauer, H. (2020), "The relationship between digitization and servitization: the role of servitization in capturing the financial potential of digitization", Technological Forecasting and Social Change, Vol. 151, pp. 1-9.

Kohtamäki, M., Parida, V., Oghazi, P., Gebauer, H. and Baines, T. (2019), "Digital servitization business models in ecosystems: a theory of the firm", Fournal of Business Research, Vol. 104, pp. 380-392.

Koskela-Huotari, K. and Vargo, S.L. (2016), "Institutions as resource context", Fournal of Service Theory and Practice, Vol. 26 No. 2, pp. 163-178.
Kowalkowski, C., Gebauer, H. and Oliva, R. (2017), "Service growth in product firms: past, present, and future", Industrial Marketing Management, Vol. 60, pp. 82-88.

Kowalkowski, C., Kindström, D. and Gebauer, H. (2013), "ICT as a catalyst for service business orientation", fournal of Business E Industrial Marketing, Vol. 28 No. 6, pp. 506-513.

Luoto, S., Brax, S.A. and Kohtamäki, M. (2017), "Critical Meta-analysis of servitization research: constructing a model-narrative to reveal paradigmatic assumptions", Industrial Marketing Management, Vol. 60, pp. 89-100.

Lusch, R.F. and Nambisan, S. (2015), "Service innovation: a service-dominant logic perspective”, MIS Quarterly, Vol. 39 No. 1, pp. 155-175.

Lusch, R.F. and Vargo, S.L. (2014), "The Service-Dominant logic of marketing: Dialog, debate, and directions", Routledge: London, ISBN 978-0765614919.

Maglio, P.P., Srinivasan, S., Kreulen, J.T. and Spohrer, J. (2006), "Service systems, service scientists, SSME, and innovation", Communications of the ACM, Vol. 49 No. 7, pp. 81-85.

Martin, P.C.G., Schroeder, A. and Bigdeli, A.Z. (2019), "The value architecture of servitization: expanding the research scope", Fournal of Business Research, Vol. 104, pp. 438-449.

Martín-Peña, M.L., Díaz-Garrido, E. and Sánchez-López, J. M. (2018), "The digitization and servitization of manufacturing: a review on digital business models", Strategic Change, Vol. 27 No. 2, pp. 91-99.

Nenonen, S. and Storbacka, K. (2020), “Don't adapt, shape! use the crisis to shape your minimum viable system - and the wider market", Industrial Marketing Management, Vol. 88, pp. 265-271.

Ng, I.C.L. and Wakenshaw, S.Y.L. (2017), "The internet-ofthings: review and research directions", International fournal of Research in Marketing, Vol. 34 No. 1, pp. 3-21.

Normann, R. (2001), "From value chain to value constellation", Harvard Business Review, pp. 65-77.

Paluch, S., Antons, D., Brettel, M., Hopp, C., Salge, T.O., Piller, F. and Wentzel, D. (2020), "Stage-gate and agile development in the digital age: promises, perils, and boundary conditions", fournal of Business Research, Vol. 110, pp. 495-501.

Paschou, T., Adrodegari, F., Perona, M. and Saccani, N. (2018), "Digital servitization in manufacturing as a new stream of research: a review and a further research agenda", in Gallouj F. and Djellal F. (Eds), A Research Agenda for Service Innovation, (pp. 148-165), Edward Elgar Publishing, Cheltenham.

Paschou, T., Rapaccini, M., Adrodegari, F. and Saccani, N. (2020), "Digital servitization in manufacturing: a systematic literature review and research agenda", Industrial Marketing Management, Vol. 89, pp. 1-15. (in press).

Pels, J., Barile, S., Saviano, M., Polese, F. and Carrubbo, L. (2014), "The contribution of vSa and SDL perspectives to strategic thinking in emerging economies", Managing Service Quality, Vol. 24 No. 6, pp. 565-591.

Peters, L.D., Nenonen, S., Polese, F., Frow, P. and Payne, A. (2020), "Viability mechanisms in market systems: prerequisites for market shaping", fournal of Business $\mathcal{E}$ Industrial Marketing, pp. 1-10. 
Polese, F., Carrubbo, L., Bruni, R. and Maione, G. (2017a), "The viable system perspective of actors in eco-systems", The TQM fournal, Vol. 29 No. 6, pp. 783-799.

Polese, F., Carrubbo, L., Bruni, R. and Caputo, F. (2018b), "Enabling actors' viable behaviour: reflections upon the link between viability and complexity within smart service system", International Fournal of Markets and Business Systems, Vol. 3 No. 2, pp. 111-119.

Polese, F., Carrubbo, L., Caputo, F. and Megaro, A. (2018a), "Co-creation in action: an acid test of smart service systems viability”, Exploring Services Science, IESS 2018, Springer.

Polese, F., Barile, S., Caputo, F., Carrubbo, L. and Walletzky, L. (2018c), "Determinants for value cocreation and collaborative paths in complex service systems: a focus on (smart)", Service Science, Vol. 10 No. 4, pp. 379-477.

Polese, F., Pels, J., Tronvoll, B., Bruni, R. and Carrubbo, L. (2017b), "A4A relationships", Fournal of Service Theory and Practice, Vol. 27 No. 5, pp. 1040-1056.

Polova, O. and Thomas, C. (2020), "How to perform collaborative servitization innovation projects: the role of servitization maturity", Industrial Marketing Management, Vol. 90, pp. 231-251.

Powers, T.L., Sheng, S. and Li, J.J. (2016), "Provider and relational determinants of customer solution performance", Industrial Marketing Management, Vol. 56, pp. 14-23.

Ramaswamy, V. (2020), "Leading the experience ecosystem revolution: innovating offerings as interactive platforms", Strategy E Leadership, Vol. 48 No. 3, pp. 3-9.

Ramaswamy, V. and Ozcan, K. (2018), "What is co-creation? An interactional creation framework and its implications for value creation", Fournal of Business Research, Vol. 84, pp. 196-205.

Reim, W., Sjodin, D. and Parida, V. (2018), "Mitigating adverse customer behaviour for product-service system provision: an agency theory perspective", Industrial Marketing Management, Vol. 74, pp. 150-161.

Russo Spena, T. and Mele, C. (2020), "Practising innovation in the healthcare ecosystem: the agency of third-party actors", Fournal of Business E Industrial Marketing, Vol. 35 No. 3, pp. 390-403.

Rymaszewska, A., Helo, P. and Gunasekaran, A. (2017), "IoT powered servitization of manufacturing - an exploratory case study", International Fournal of Production Economics, Vol. 192, pp. 92-105.

Savić, D. (2019), "From digitization, through digitization, to digital transformation", Online Searcher, Vol. 43 No. 1, pp. 36-39.

Sjödin, D., Parida, V., Kohtamäki, M. and Wincent, J. (2020), "An agile co-creation process for digital servitization: a micro-service innovation approach", fournal of Business Research, Vol. 112(in press).

Sklyar, A., Kowalkowski, C., Tronvoll, B. and Sörhammar, D. (2019), "Organizing for digital servitization: a service ecosystem perspective", Fournal of Business Research, Vol. 104, pp. 450-460.

Storbacka, K. (2018), "Extending Service-Dominant logic", The SAGE Handbook of Service-Dominant Logic, pp. 635-638.

Storbacka, K. and Nenonen, S. (2015), "Learning with the market: facilitating market innovation", Industrial Marketing Management, Vol. 44, pp. 73-82.
Storbacka, K., Frow, P., Nenonen, S. and Payne, A. (2012), "Designing business models for value co-creation", in Vargo, S.L. and Lusch, R.F. (Eds), "Special Issue - toward a Better Understanding of the Role of Value in Markets and Marketing", Review of Marketing Research, Vol. 9, pp. 51-78.

Storbacka, K., Brodie, R.J., Böhmann, T., Maglio, P.P. and Nenonen, S. (2016), "Actor engagement as a microfoundation for value co-creation", fournal of Business Research, Vol. 69 No. 8, pp. 3008-3017.

Svahn, F., Mathiassen, L. and Lindgren, R. (2017), "Embracing digital innovation in incumbent firms: how Volvo cars managed competing concerns", MIS Quarterly, Vol. 41 No. 1, pp. 239-253.

Tavory, I. and Timmermans, S. (2014), Abductive Analysis: Theorizing Qualitative Research, University of Chicago Press, Chicago.

Tronvoll, B. (2017), "The actor: the key determinator in service ecosystems", Systems, Vol. 5 No. 2, p. 38.

Tronvoll, B., Sklyar, A., Sörhammar, D. and Kowalkowski, C. (2020), "Transformational shifts through digital servitization", Industrial Marketing Management, Vol. 89, pp. 1-13. (in press).

Ulaga, W. and Reinartz, W.J. (2011), "Hybrid offerings: how manufacturing firms combine goods and services successfully", fournal of Marketing, Vol. 75 No. 6, pp. 5-23.

Vargo, S.L. and Lusch, R.F. (2008), "Service-dominant logic: continuing the evolution", Fournal of the Academy of Marketing Science, Vol. 36 No. 1, pp. 1-10.

Vargo, S.L., Lusch, R.F. (2011), "It's all B2B ... and beyond: toward a systems perspective of the market", Industrial Marketing Management, Vol. 40 No. 2, pp. 181-187.

Vargo, S.L. and Lusch, R.F. (2016), "Institutions and axioms: an extension and update of service-dominant logic", Fournal of the Academy of Marketing Science, Vol. 44 No. 1, pp. 5-23.

Vargo, S.L. and Lusch, R.F. (2017), "Service-dominant logic 2025”, International Fournal of Research in Marketing, Vol. 34 No. 1, pp. 46-67.

Vendrell-Herrero, F., Parry, G., Bustinza, O.F. and Gomes, E. (2018), "Digital business models: taxonomy and future research avenues", Strategic Change, Vol. 27 No. 2, pp. 87-90.

von Bertalanffy, L. (1968), General System Theory, George Braziller, New York, NY.

Weber, Y. and Tarba, S.Y. (2014), "Strategic agility: a state of the art introduction to the special section on strategic agility", California Management Review, Vol. 56 No. 3, pp. 5-12.

Yin, R.K. (2017), Case Study Research and Applications: Design and Methods, Thousand Oaks, CA: Sage, 6nd eds.

\section{Further reading}

Barile, S., Orecchini, F., Saviano, M. and Farioli, F. (2018), "People, technology, and governance for sustainability: the contribution of systems and cybersystemic thinking", Sustainability Science, Vol. 13 No. 5, pp. 1197-1208. 


\section{Appendix. Interview guide themes}

General questions:

- What is your role in the company?

- What are the company's main activities?

- What was the company's revenue over the last year?

- Who are the company's most important business customers geographically?

- How many employees does the company currently have?

Framework-related questions:

- Why has the company undertaken the digital servitization?

- Which are actors involved in the shift to digital servitization?

- What are the main resources and capabilities required by digital servitization?

- What are roles of organizational units, internal and external customers and other actors in the digital servitization project?

- How do relations occur within the companies and across other actors?

- How are relations managed within the companies and across other actors?

- What activities are needed for the company to offer advanced services?

- What activities are critical in facilitating digital servitization?

- How do digital technologies work to support service implementation?

- Are there advantages/disadvantages of adopting digital technologies for advanced service development and implementation?

- What is the strategic vision of the company toward technology-enabled service implementation?

\section{About the authors}

Maria Vincenza Ciasullo is an Associate Professor in Business Management at the University of Salerno, Italy, since 2005. She received the $\mathrm{PhD}$ degree in management from the University of Naples, Italy, in 2004. She is also an Affiliated Professor in Management at University of Isfahan, Iran. Her current research focus on: Digital Transformation and Business Models, Sustainability management, Service innovation and value co-creation. On these topics, she has published in International journal such as International Entrepreneurship and Management Fournal, Business Strategy and Environment, The TQM fournal, Studies of Higher Education, Current Issue in Tourism, Futures and Land Use Policy. She has been awarded by Emerald (Highly
Commended Paper Award, 2018; 2019). orcid ID 00000003-2052-551X. Maria Vincenza Ciasullo is the corresponding author and can be contacted at: mciasullo@ unisa.it

Francesco Polese is a Full professor of Business Management at the Dept. of Business Studies - Management \& Innovation Systems in Salerno University where he teaches Service Management, Marketing, Healthcare Management. $\mathrm{He}$ is Director and founder of Interdept. Centre Simas (Innovation Systems and Healthcare Management) and author of several books dealing with networks and management in healthcare environment. With a system thinking perspective, his research interests cover the Viable Systems Approach, Service Science, Complexity. Since 2009 he is co-chair, along with Evert Gummesson and Cristina Mele, of the Naples Forum on Service (www. naplesforumonservice.it)

Raffaella Montera is Adjunct Professor of Economics and Business Management at University of Salerno (Italy) Department of Management \& Innovation Systems and Adjunct Professor of Management and Marketing of Cultural Heritage at University of Salerno (Italy) - School of Specialization in Archaeological Heritage. She is engaged in training activities in the master's degrees and advanced training courses. She is also a Teaching Fellow in Business Strategies at University of Salerno (Italy) - Department of Management \& Innovation Systems. She holds a PhD in Marketing and Business Communication at University of Salerno (Italy) - Department of Business Studies. Her researches are focused on Strategic Management, Marketing Management, Sustainability, Internationalization, Tourism and Hospitality. She is author of a monograph, contributions in Conference proceedings and in national and international journals.

Luca Carrubbo is in charge of Department of Business Studies, Management and Innovation Systems since 2020 as Assistant Professor (RTD-B) in Business Management. $\mathrm{He}$ is graduated cum laude in Business Management at University of Naples "Federico II", $\mathrm{PhD}$ in Business Management since 2011 and Licensed as Associate Professor in Business Management since 2018. Since 2012 he is Visiting Professor at Masaryk University of Brno (CZ) for the course of Marketing strategies in service business within the $\mathrm{T}$-shaped international educational program of sponsored by SSMED. He is Member of AIDEA, SIM and SIMA Associations since 2017, ASVSA Member since 2011, Council Member of SIMAS Interdepartmental Research Centre focused of Innovation Systems and Healthcare Management since 2019. 